\title{
EVALUATION OF HIBISCUS GUM AS POTENTIAL CARRIER FOR COLON SPECIFIC DRUG DELIVERY
}

\author{
*Dhruv Dev ${ }^{1}$, Patel Kannu Bhai Ramesh Bhai ${ }^{2}$ \\ Research Scholar, JJT University, Jhunjhunu, Rajashthan, India \\ Shri B. M. Shah College of Pharmaceutical Education and Research, Modasa, Gujarat, India \\ *Corresponding Author's E mail: ddagnihotri@gmail.com
}

\begin{abstract}
:
The potential of hibiscus gum for colon specific delivery of 5-fluorouracil is evaluated in this study. The hibiscus gum was extracted from Hibiscus esculentus and was characterized for viscosity, swelling index and IR spectra. The studies showed that the gum was hydrophilic, acidic in nature with swelling index of $450 \%$. The viscosity of $0.5 \% \mathrm{w} / \mathrm{v}$ solution of gum is $82 \mathrm{cps}$. The FT-IR studies showed that the gum contained hydroxyl and carboxylic acid. The hibiscus gum -based matrix tablets were prepared by direct compression method using microcrystalline cellulose, Lactose, magnesium stearate and talc. The tablets were evaluated for various parameters like hardness, friability, drug content weight variation and in vitro drug release profile with and without caecal content. The studies showed that the all the batches have hardness between 5-6, drug content in the range 98.55 to $99.45 \%$. Friability and weight variation were within the limit. In vitro studies showed that as the amount of hibiscus gum increases the drug release decreases from the matrix tablet. Formulation F5 showed optimum results and hence selected for the coating by hibiscus gum solution. The coated tablet release only $5 \%$ of th drug in 4 hours. The same formulation releases the maximum amount of drug when $2 \%$ caecal content was added to the $\mathrm{pH} 6.8$ buffer In vitro results indicate that hibiscus gum can be used as carrier to achieve enzyme-triggered fluorouracil release

Keywords: 5- fluorouracil, Hibiscus Gum, colon, Lactose
\end{abstract}

\section{INTRODUCTION:}

Colon specific drug delivery has the advantage for effective treatment of various colon related diseases such as Colon cancer, Ulcerative colitis, inflammatory bowel disease, Crohn's disease, infections etc. Further the colon is believed to be suitable absorption site for peptides and protein drugs due to relative low proteolytic enzyme activity, near neutral $\mathrm{pH}$ and a much longer transit period. Site-specific drug delivery to the colon is considered for the past few years in order to develop drug delivery systems that are able to release drugs specifically in the colon in a predictable and reproducible manner. The importance of site specific drug delivery to colon is for the treatment of diseases associated with the colon, reducing the side effects and reducing the dose.

Various approaches like pH-dependent release, timedependent release and microbial enzyme triggered release. $\mathrm{pH}$ dependent systems have the disadvantage of specificity as there is minor change in variation in $\mathrm{pH}$ between small intestine and colon. The time dependent system has the limitation that the drug may be released in the small intestine with small variation of small intestine transit time. Recently microbial enzyme triggered approach based on polysaccharides have drawn much attention due to their degradation by colon microbial enzymes. Various polysaccharides like Guar gum, Chitosan, Pectin, Inulin etc. were used for colonic delivery of drug but with limited success.

The aim of present investigation was to evaluate hibiscus gum as carrier for the formulation of colon specific drug delivery that offer protection of drug in the upper GIT and release it in the colon. Formulations like matrix tablets and tablet with hibiscus gum coating were studied to optimize the colon specific drug delivery of a model drug.[1-3]

\section{MATERIALS AND METHODS}

\section{Materials:}

5-Fluorouracil was a gift sample from Intas Pharmaceutical Ltd., Ahmedabad,India. MCC, lactose and other chemicals were obtained from $\mathrm{CDH}$ Chemical.

Extraction of gum from Hibiscus esculentus: Hibiscus esculentus fruits were thoroughly washed with water, deseeded, crushed and soaked in water overnight. The gum solution was separated through the muslin cloth. The marc was again soaked in water overnight. The gum solution obtained was separated from marc by filtration and both the filtrates were mixed together. This gum solution was concentrated to half of its initial volume on a water bath. The crude gum was then precipitated with ethanol. Precipitates obtained were filtered and washed with ethanol. The gum was dried in oven at $45^{\circ} \mathrm{C}$ for 12 hours. The dried gum was purified by dissolving in purified water and then precipitated with ethanol The dried gum was treated with $0.3 \mathrm{~N} \mathrm{Ba}(\mathrm{OH}) 2-5 \%$ aqueous $\mathrm{ZnSO} 4.7 \mathrm{H} 2 \mathrm{O}$ for deproteinization. The precipitates were dried in oven at $45^{0} \mathrm{C}$ for 12 hours.[4-5]

\section{Characterization of Gum:}

The viscosity and $\mathrm{pH}$ of $0.5 \% \mathrm{w} / \mathrm{v}$ hibiscus gum solution were determined using digital $\mathrm{pH}$ meter and Ostwald's viscometer respectively. Further the gum was characterized for IR spectra and swelling index.

\section{Preparation of Matrix Tablet:}

Matrix tablets of 5-fluorouracil were prepared by direct compression method using various concentrations of hibiscus gum, Microcrystalline cellulose, lactose, Magnesium stearate and talc as given in the table: 
Table 1: Showing composition of Matrix tablet

\begin{tabular}{|c|c|c|c|c|c|c|}
\hline Formulation & 5- fluorouracil (mg) & $\begin{array}{l}\text { Hibiscus gum } \\
(\mathrm{mg})\end{array}$ & MCC (mg) & $\begin{array}{l}\text { Lactose } \\
\text { (mg) }\end{array}$ & $\begin{array}{l}\text { Magnesium } \\
\text { Stearate (mg) }\end{array}$ & $\begin{array}{l}\text { Talc } \\
\text { (mg) }\end{array}$ \\
\hline F1 & 150 & 25 & 100 & 175 & 5 & 5 \\
\hline F2 & 150 & 50 & 100 & 150 & 5 & 5 \\
\hline F3 & 150 & 75 & 100 & 125 & 5 & 5 \\
\hline F4 & 150 & 100 & 100 & 100 & 5 & 5 \\
\hline F5 & 150 & 125 & 100 & 75 & 5 & 5 \\
\hline F6 & 150 & 150 & 100 & 50 & 5 & 5 \\
\hline F7 & 150 & 175 & 100 & 25 & 5 & 5 \\
\hline
\end{tabular}

\section{Preparation of Film coated tablet of 5-fluorouracil:}

The selected batch of 5-fluorouracil tablets was further coated with $0.5 \% \mathrm{w} / \mathrm{v}$ solution of Hibiscus gum in water using PEG 400 as plasticizer. Different batches with varied amount of coating were made by varying duration of coating.

\section{Evaluation of Tablets:}

The prepared tablets were evaluated for hardness, weight variation, friability and drug content using standard methods. $^{7-9}$

In vitro release studies: The in vitro drug release from different batches were determined in dissolution test apparatus using different $\mathrm{pH}$ mediums like $\mathrm{pH}$ 1.2, 7.4 and 6.8 buffers either in presence or absence of rat caecal content. The dissolution studies were carried out for first 2 hours using $\mathrm{pH} 1.2$ buffer. Then the dissolution medium was changed to phosphate buffer $\mathrm{pH} 7.4$ and tested for drug release for $2 \mathrm{~h}$ as the average small intestinal transit time is about 2 h. After 3 hours the dissolution studies were carried out in $\mathrm{pH} 6.8$ phosphate buffered saline for further 8 hours. The studies were also carried out in $\mathrm{pH} 6.8$ phosphate buffered saline containing $2 \% \mathrm{w} / \mathrm{v}$ of rat caecal contents. As the caecum is naturally anaerobic, the experiment was carried out with continuous $\mathrm{CO}_{2}$ supply into the beaker. At various time intervals, $5 \mathrm{ml}$ of the dissolution sample was withdrawn and was analyzed by UV Visible Spectrophotometer at $267 \mathrm{~nm}$.

\section{RESULTS AND DISCUSSION}

Viscosity and Swelling properties:

The viscosity of $0.5 \% \mathrm{w} / \mathrm{v}$ solution of Hibiscus gum was $82 \mathrm{cps}$. The release rate from polymer gel is inversely proportional to the viscosity of the gel. As the hibiscus gum is highly viscous it showed more resistant to release of drug from the matrix. The $\mathrm{pH}$ of gum solution was found to be 6.5 which is slight acidic because of presence of uronic acid. Swelling index of the gum is about $200 \%$ for the first 1 hour and the maximum is $450 \%$ in 24 hours which showed hydrophilic nature of the gum.

\section{IR spectra of Hibiscus Gum:}

The FTIR spectrum of pure gum is shown in Figure 1. The spectra showed a strong hydrogen bond $\mathrm{O}-\mathrm{H}$ stretching at $3403.4 \mathrm{~cm}^{-1}$ indicating presence of primary alcohol and $\mathrm{O}$ $\mathrm{H}$ of carboxylic acid. A C-H stretch at $2929.7 \mathrm{~cm}^{-1}$ showed the presence of $-\mathrm{CH}_{2}$ moieties in the sample. Peak at $1652.6 \mathrm{~cm}^{-1}$ indicating the presence of $\mathrm{C}=\mathrm{O}$ group in the gum. Peak of $1252.6 \mathrm{~cm}^{-1}$ showed C-O stretching and a bending band for $\mathrm{O}-\mathrm{H}$ at 1419.3. Peak at $1042 \mathrm{~cm}^{-1}$ indicated the presence of primary alcohol and also C-C stretching.

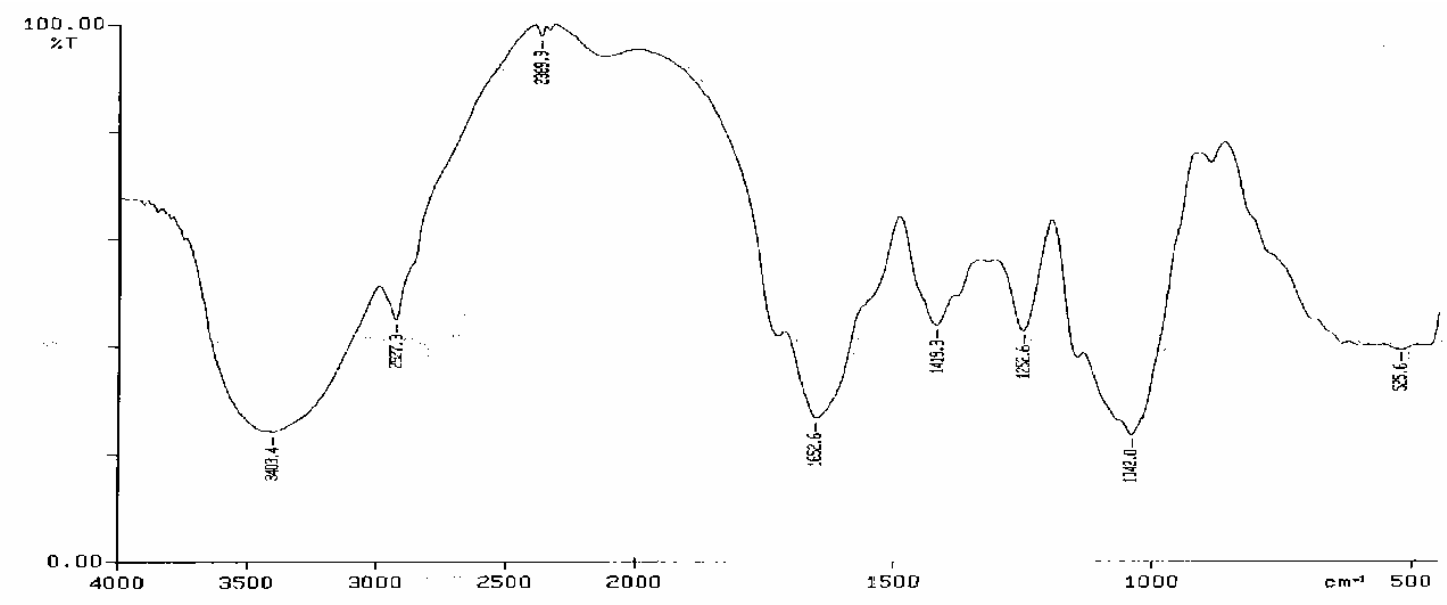

\section{Hardness of Matrix tablets:}

All the batches of matrix tablets showed hardness within prescribed range of 5-6 except the formulation F7 in which the surface of the tablet is not smooth because of stickiness of hibiscus gum. The weight variation of different batches was within the limit. The drug content was found to be in the range of 98.55 to $99.45 \%$.

\section{In vitro release studies:}

The in vitro release studies of 5-fluorouracil from matrix tablets were shown in the figure 2 . 


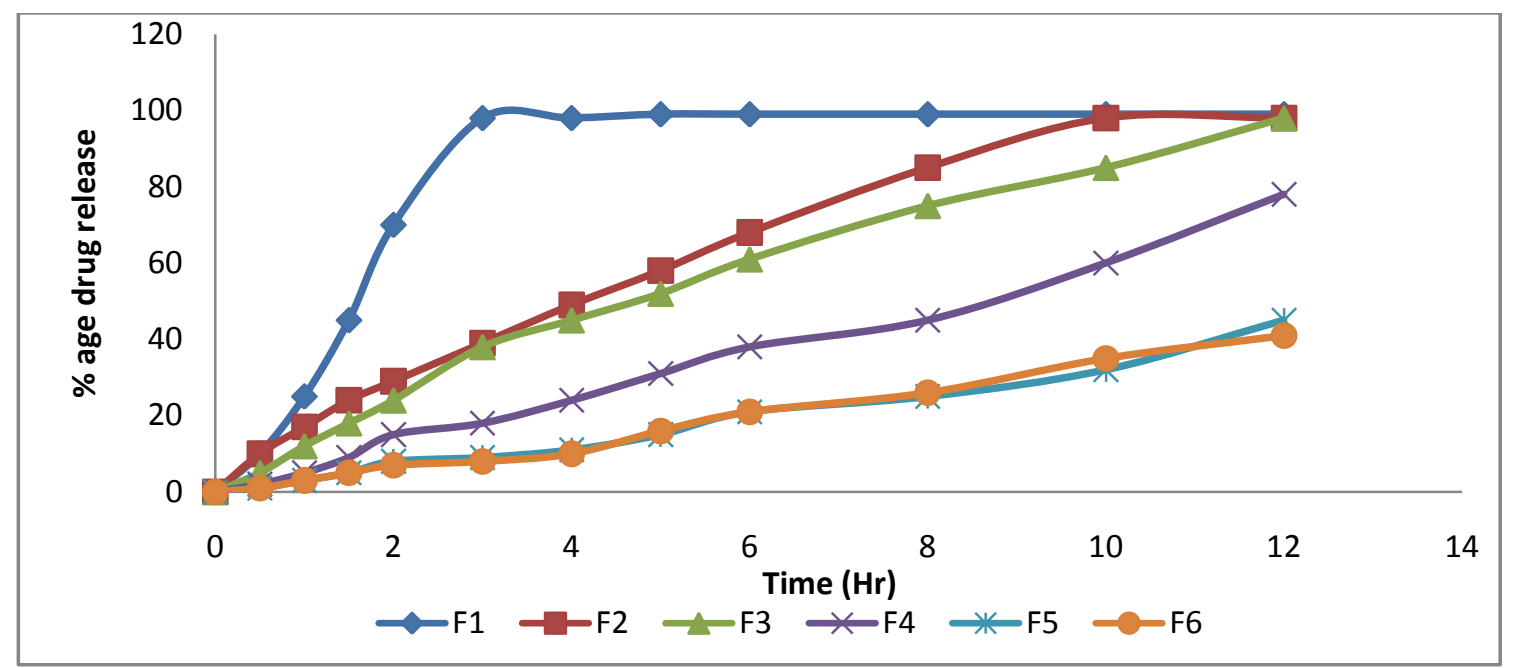

Figure 2: Drug release profiles of 5-fluorouracil from Hibiscus gum matrix tablets

From the release profile it was shown that the drug release decrease with the increase in the concentration of hibiscus gum and decrease in concentration of lactose which is soluble in water. Formulation F1 to F3 showed $98.21 \%$ to $45.74 \%$ drug release within first 4 hours and almost all the drug released within 10 hours. Formulation F5 and F6 showed less than 15\% drug release within first 4 hours which was due to higher concentration hibiscus gum. So for coating the formulation F5 was selected. Formulation F5 coated with $0.5 \%$ hibiscus gum solution was subjected to Drug release studies and the comparative release was showed in figure 3

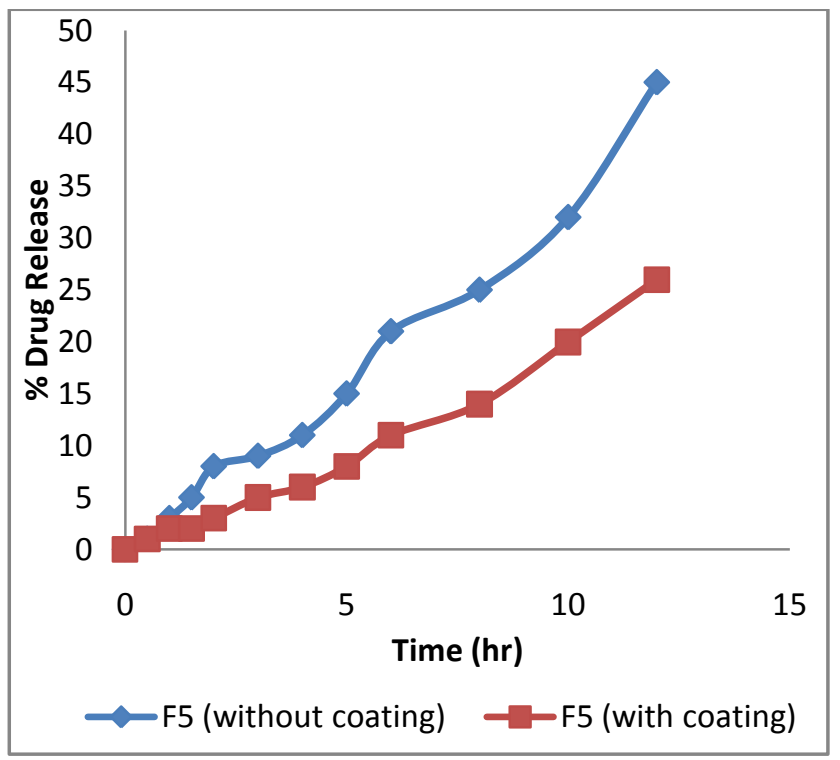

Figure 3: Comparative release profile of formulation F5 with or without coating.

From fig. 3 it was observed that the formulation F5 coated with $0.5 \%$ hibiscus gum solution showed more resistance for the drug release. This may be due to formation of uniform protective layer membrane of polymer gel which refrain the release of drug.

The release profile of formulation F5 (coated) with and without ceacal content was shown in Figure 4

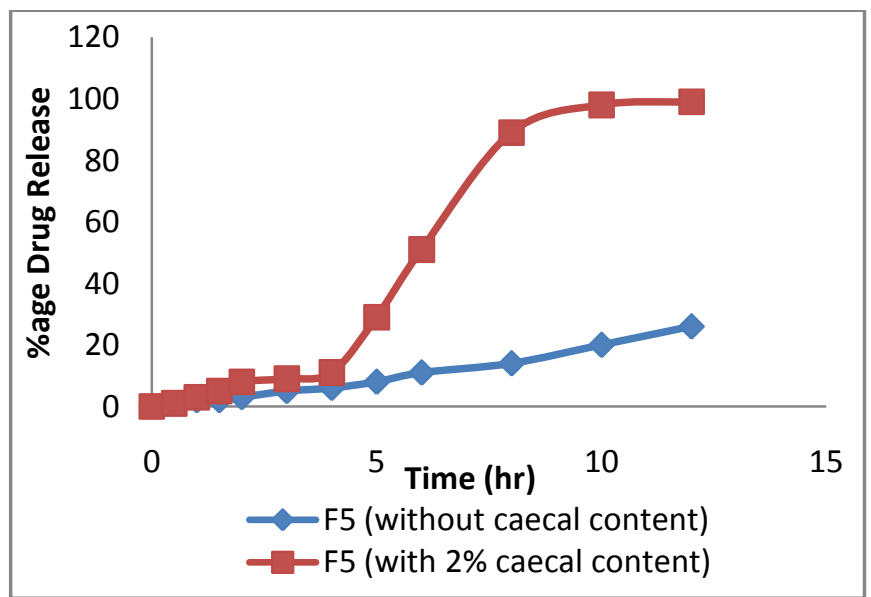

Figure 4: Drug release profiles of 5-fluorouracil from coated formulation F5 with and without caecal content.

From figure 4 it was observed that after 4 hrs when the formulation F5 (coated) was subjected to $\mathrm{pH} 6.8$ buffer with $2 \%$ caecal content there occur abrupt release of drug from the formulation which showed microbial degradation of coating of hibiscus gum in the colonic fluid.

\section{CONCLUSION:}

Hibiscus gum controlled the release of 5-fluorouracil from the matrix tablet but its effectiveness increased when it was used as coating polymer. Further it was concluded that the release of drug from the matrix tablet is by microbial enzyme triggered mechanism. The study suggested that hibiscus gum may be an ideal candidate for the formulation of matrix tablet of as coating material for targeting drug to the colon.

\section{ACKNOWLEDGEMENT}

The author wishes to acknowledge the Principal, Shivalik college of Pharmacy, Nangal for providing the chemicals and Labs and also Registrar JJT University, Jhunjhunu, Rajasthan as well as SAIF, Punjab University Chandigarh for Providing IR data.

CONFLICT OF INTEREST: The author does not have any conflict of interest. 


\section{REFERENCES:}

1) Patel M., Shah T. and Amin A., Therapeutic opportunities in colon-specific drug-delivery systems. Crit. Rev. Ther. Drug Carrier Syst., 24(2), (2007),147-202.

2) Janovska L., Vetchy D. and Rabiskova M., New systems for colonic drug targeting. Ceska Slov Farm., 55(5), (2006), 203209.

3) Ishibashi T., Ikegami K., Kubo H., Kobayashi M., Mizobe M. and Yoshino H., Evaluation of colonic absorbability of drugs in dogs using a novel colon targeted delivery capsule (CTDC). $J$. Control. Release, 59, (1999), 361-376.

4) Eckburg P.B., Bik EM., Bernstein CN., Purdom E., Dethlefsen L., Sargent M., Gill SR., Nelson KE., and Relman DA., Diversity of the human intestinal microbial flora. Science, 308, (2005), 1635-1638.

5) McConnell EL., Basit AW. and Murdan S., Colonic antigen administration induces significantly higher humoral levels of colonic and vaginal $\operatorname{Ig} \mathrm{A}$, and serum $\operatorname{IgG}$ compared to oral administration. Vaccine, 26, (2008), 639-646.

6) Vandamm TF., Lenourry A., Charrueau C. and Chaumeil JC. The use of polysaccharides to target drugs to the colon. Carbohydrate Polymers, 48(3), (2002), 219-231.

7) Jain A., Gupta Y. and Jain SK., Perspectives of biodegradable natural polysaccharides for site-specific drug delivery to the colon. J. Pharm. Pharmaceut. Sci., 10(1), (2007) 86-128.

8) McConnell EL., Fadda HM. and Basit AW., Gut instincts: Explorations in intestinal physiology and drug delivery. Int. J. Pharm., 364(2), (2008), 213-226.

9) Asghar LF. and Chandran S., Design and evaluation of $\mathrm{pH}$ modulated controlled release matrix systems for colon specific delivery of indomethacin. Pharmazie, 63(10), (2008), 736-42. 